\title{
Tracing the fate and transport of secondary plant metabolites in a laboratory mesocosm experiment by employing mass spectrometric imaging
}

\author{
Anna C. Crecelius ${ }^{1,2}$ - Beate Michalzik ${ }^{3}$ - Karin Potthast $^{3} \cdot$ Stefanie Meyer $^{3}$. \\ Ulrich S. Schubert ${ }^{1,2}$
}

Received: 6 December 2016 / Revised: 28 February 2017 / Accepted: 16 March 2017 / Published online: 29 March 2017

(C) The Author(s) 2017. This article is published with open access at Springerlink.com

\begin{abstract}
Mass spectrometric imaging (MSI) has received considerable attention in recent years, since it allows the molecular mapping of various compound classes, such as proteins, peptides, glycans, secondary metabolites, lipids, and drugs in animal, human, or plant tissue sections. In the present study, the application of laser-based MSI analysis of secondary plant metabolites to monitor their transport from the grass leaves of Dactylis glomerata, over the crop of the grasshopper Chorthippus dorsatus to its excrements, and finally in the soil solution is described. This plant-herbivore-soil pathway was investigated under controlled conditions by using laboratory mesocosms. From six targeted secondary plant metabolites (dehydroquinic acid, quinic acid, apigenin, luteolin, tricin, and rosmarinic acid), only quinic acid, and dehydroquinic acid, an in-source-decay (ISD) product of quinic acid, could be traced in nearly all compartments. The tentative identification of secondary plant metabolites was performed by MS/MS analysis of methanol extracts prepared from the investigated compartments, in both the positive and negative ion mode, and subsequently compared with the results generated from
\end{abstract}

Electronic supplementary material The online version of this article (doi:10.1007/s00216-017-0325-7) contains supplementary material, which is available to authorized users.

Anna C. Crecelius

anna.crecelius@uni-jena.de

1 Laboratory of Organic and Macromolecular Chemistry (IOMC), Friedrich Schiller University Jena, Humboldtstrasse 10, 07743 Jena, Germany

2 Jena Center for Soft Matter (JCSM), Friedrich Schiller University Jena, Philosophenweg 7, 07743 Jena, Germany

3 Institute of Geography, Friedrich Schiller University Jena, Löbdergraben 32, 07743 Jena, Germany the reference standards. Except for tricin, all secondary metabolites could be tentatively identified by this approach. Additional liquid-chromatography mass spectrometry (LCMS) experiments were carried out to verify the MSI results and revealed the presence of quinic acid only in grass and chewed grass, whereas apigenin-hexoside-pentoside and luteolin-hexoisde-pentoside could be traced in the grasshopper body and excrement extracts. In summary, the MSI technique shows a trade-off between sensitivity and spatial resolution.

Keywords Laser desorption/ionization - Time-of-flight . Mass spectrometric imaging $\cdot$ Mesocosm $\cdot$ Secondary plant metabolites

\section{Introduction}

In view of current climate change, more extreme weather phenomena are projected to occur, which, in turn, favor ecosystem disturbances such as mass outbreaks of herbivore insects $[1,2]$. Due to their feeding and excreting activities, insect pests are known to facilitate the release of nutrients previously bound in plants, which have been found to be particularly important for changes in the rates of nutrient cycling due to the prompt availability to soil microbes and plants [3, 4]. Furthermore, recent studies point to herbivore-induced alterations in the timing and the quality of organic matter fractions reaching the forest floor as compared to organic matter in litterfall and the potential impact on belowground processes [5]. As a consequence, the knowledge of the effect of, e.g., herbivore feeding activity on the cycling of specific organic substances in an ecosystem and their use as biomarkers for tracing the source of dissolved organic matter (DOM) in soil is of great value. 
To shade more light into the impact of insect feeding activity on the composition of DOM, a laboratory mesocosm experiment comprising the grass species Dactylis glomerata and the grasshopper species Chorthippus dorsatus was conducted. The idea was to follow the abundance and compositional change of organic substances along a plant-herbivore-excretions (feces)soil solution pathway by the application of emerging visualization techniques, namely laser desorption/ionization time-of-flight mass spectrometric imaging (LDI-TOF MSI) and matrix-assisted laser desorption/ionization time-of-flight mass spectrometric imaging (MALDI-TOF MSI) $[6,7]$. The latter technique requires the evaluation of suitable matrices for the analysis of secondary plant metabolites $[8,9]$, in particular when different objects (grass leaves, grasshopper, excrements) are analyzed.

The analysis of leaf surfaces by laser-based MSI techniques has been often described in recent literature [10,11], even the quantification of plant surface metabolites [12]; however, the common grass species $D$. glomerata has up to now not been investigated. A few studies about the MALDI MSI analysis of insects, such as beetles [13], flies [14-16], and honeybees [17], can be found in the literature; however, locusts have only been imaged employing desorption electrospray ionization (DESI) to show the distribution of the pharmaceutical compound terfenadine and its metabolites [18].

In the current study, special emphasis was drawn to the role of secondary plant metabolites in organic matter cycling, since only very little knowledge is available so far [19]. In particular, the insect-mediated formation and fate of polyphenols from plant tissue via insect excretion to their ultimate mineralization is still uncertain. Polyphenols, thereby, are the most distributed class of secondary metabolites and, e.g., contribute to the plant color, defend the plants against herbivory, and increase the plants' fitness [19, 20]. In many studies, phenolic compounds have been shown to function as allelochemicals, referring to an "interference mechanism in which live or dead plant materials including plant litter release chemicals which exert an effect (usually negative) on associated plants" [21]. For example, secondary metabolites inhibit both germination and growth of plants, thereby affecting the distribution patterns and composition of understory vegetation of forests $[22$, 23]; furthermore, they affect the growth of mycorrhizal fungi [24], inhibit feeding by various fungi [25], and potential herbivores [26, 27].

Four polyphenols (apigenin, luteolin, tricin, and rosmarinic acid) and two cyclic polyols (dehydroquinic acid and quinic acid) were evaluated as biomarkers to trace the source of DOM in soil, since they were easily detectable via MSI on the grass species D. glomerata. To the best of our knowledge, this is the first study on the application of spectrometric imaging techniques to track secondary metabolites in a model ecosystem along a cascade of different trophic levels.

\section{Materials and methods}

\section{Chemicals}

HPLC-grade methanol and water were purchased from VWR International (Dresden, Germany). Sucrose, trifluoro acetic acid, and the reference substances 3-dehydroquinic acid potassium salt, quinic acid, rosmaricic acid, tricin-5-glycoside, cryptochlorgenic acid, apigenin, apigenin-7-glycoside, luteolin, and luteolin-7-glycoside were supplied by SigmaAldrich (Steinheim, Germany). Gelatin was bought from Merck KGaA (Darmstadt, Germany). The matrices $\alpha$-cyano4-hydroxycinnamic acid ( $\alpha$-CHCA), 2,5-dihydroxybenzoic acid (DHB) were purchased from Bruker Daltonik $\mathrm{GmbH}$ (Bremen, Germany), and 1,5-diaminonaphthalene (1,5DAN) from Sigma-Aldrich.

\section{Herbivory experiments}

To trace the fate of secondary metabolites in a pasture ecosystem invaded by grasshoppers, mesocosm experiments with the common pasture grass $D$. glomerata and with homogenized pasture soil ( 0 to $16 \mathrm{~cm}$, sieved to $6 \mathrm{~mm}$ ) were conducted under controlled environmental conditions in a climatic chamber. To simulate a well-established pasture, seeds of D. glomerata were distributed homogeneously with a hole template on the soil surface of the mesocosms $(12 \mathrm{~cm}$ soil depth, $50 \mathrm{~cm}$ in diameter, about 4 seeds $/ \mathrm{dm}^{2}$ ) 1 year before the experiments started. During growth, the grass was cultivated in a climatic chamber $\left(15^{\circ} \mathrm{C}\right.$, automated weekly watering), as presented in Fig. 1a. In April 2015, the grass was cut once to a height of $4 \mathrm{~cm}$ to simulate grazing. Before the start of the herbivory experiment, grasshoppers, C. dorsatus, were caught on a grassland next to Jena. In October 2015, the herbivory experiment started when 20 grasshoppers were housed in one mesocosm and subjected to a 8 -h dark and 16-h light cycle for 5 days, as presented in Fig. 1. In parallel mesocosms without grasshopper amendment were used as control. The grasshoppers had constant access to the pasture grass. At the end of the experiment, chewed grass leaves (see Fig. 2a), grasshoppers (see Fig. 1b), feces (see Fig. 1c), and soil solutions (cold water extracts of soil samples: control and grasshopper mesocosms) were taken to conduct the visualization of polyphenols and cyclic polyols in these compartments. The respective sample preparations and applications for MSI investigations are given below:

Grass leaves Fresh chewed leaves were fixed on double-sided conductive tape $(65 \mathrm{~mm} \times 20 \mathrm{~mm}$, Plano $\mathrm{GmbH}$, Wetzlar, Germany) and attached to indium tin oxide (ITO)-coated glass slides (Bruker Daltonik GmbH, Bremen, Germany). Each grass leaf was mounted on one ITO-coated glass slide. 
Fig. 1 Laboratory mesocosm experiment: The photographs show a the mesocosms with the grown grass species $D$. glomerata in the climatic chamber; $\mathbf{b}$ a grasshopper from the species C. dorsatus; and $\mathbf{c}$ its feces. Scale bar $5 \mathrm{~mm}(\mathbf{c})$
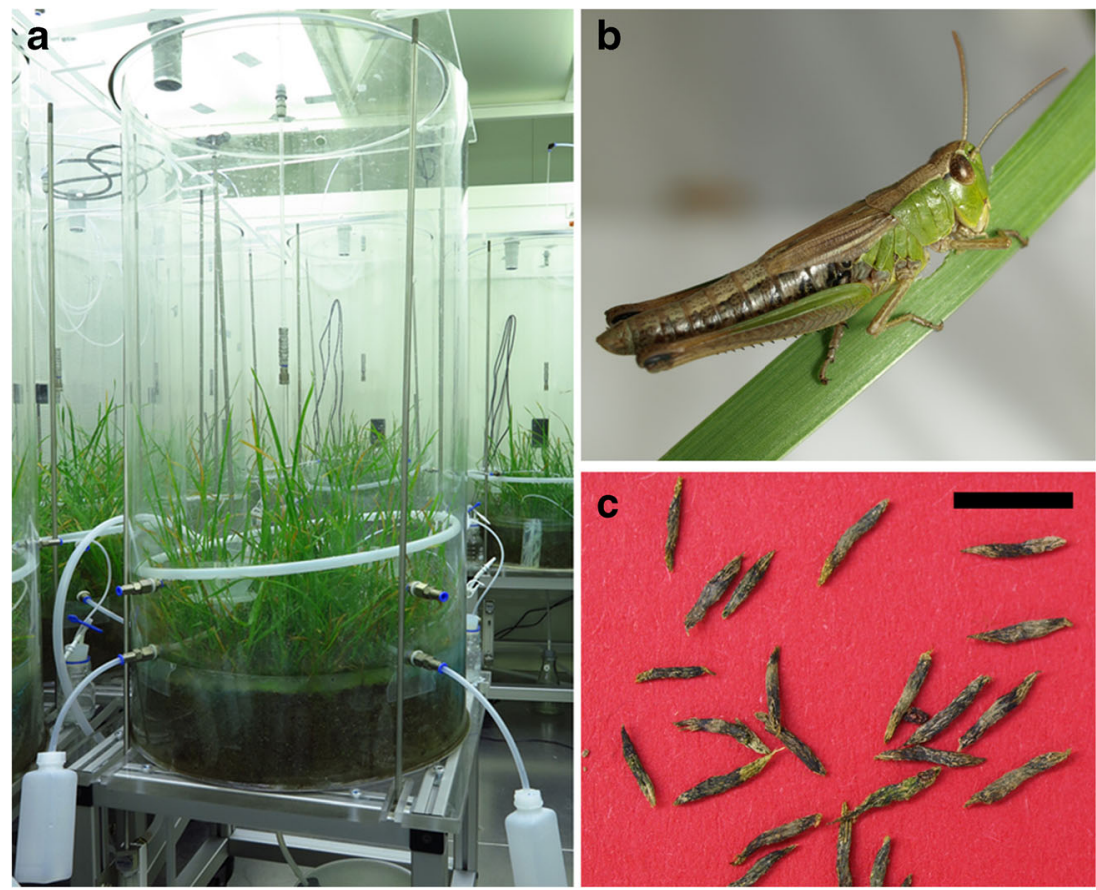

Afterwards, teaching points were added with a white paint marker and the slide was scanned with an Epson perfection v700 photo scanner (Epson Europe B. V., Amsterdam, Netherlands). Figure 2a shows such a photographic image. The matrix was either sprayed on the grass leaf using an ImagePrep device (Bruker Daltonik $\mathrm{GmbH}$ ) following the manufacture's protocol or with an air-brush device (Revell $\mathrm{GmbH}$, Bünde, Germany). For the latter method, the ITO- coated glass slide with the sample was mounted upright $25 \mathrm{~cm}$ from the air-brush outlet and $5 \mathrm{~s}$ of spraying was alternated with 1 min of air-drying. Between 10 and 15 cycles of matrix application produced a homogeneous layer of matrix crystals. Afterwards, the sample was stored in a desiccator for approximately $1 \mathrm{~h}$. The positive ion mode with $100 \mu \mathrm{m}$ spatial resolution and within a mass range of $\mathrm{m} / \mathrm{z}, 200$ to 1500 was selected for MALDI-TOF MSI analysis. a
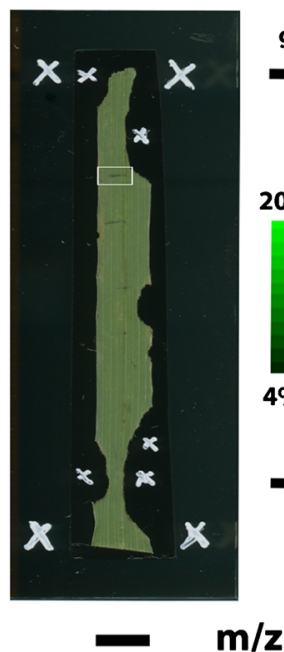

b

grasshopper bites

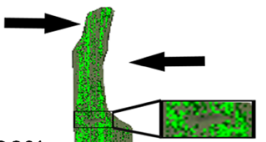

$20 \%$

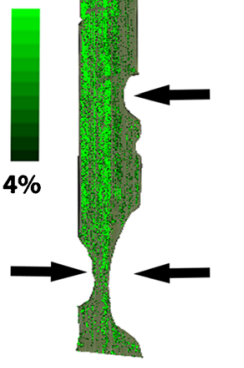

215
C

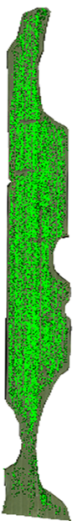

271 d

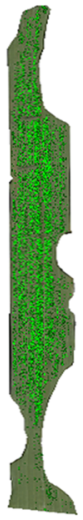

309 e

f

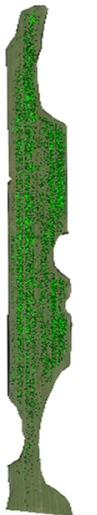

331

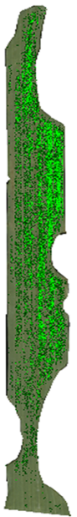

383

Fig. 2 MALDI-TOF MSI analysis of a D. glomerata leaf. a Optical image taken before the matrix application, and ion images (green color) overlaid onto the optical image showing the distribution of $\mathbf{b}$ quinic acid $(\mathrm{m} / \mathrm{z}, 215)$, $\mathbf{c}$ apigenin $(\mathrm{m} / \mathrm{z}, 271)$, d luteolin $(\mathrm{m} / \mathrm{z}, 309)$, e tricin $(\mathrm{m} / \mathrm{z}, 331)$, and $\mathbf{f}$ rosmarinic acid $(\mathrm{m} / \mathrm{z}, 383)$

Note: The assignments of the secondary plant metabolites are tentative based on the MS and MS/MS data of reference standards, as presented in the ESM, and additional MS and MS/MS experiments of methanol extracts of D. glomerata leaves, as shown in Figs. 3 and 4, respectively. The ion images are normalized using the TIC. Scale bar $5 \mathrm{~mm}$ (a) 
Grasshoppers At the end of the experiments, the gastrointestinal tract was extracted from a grasshopper body that was emerged for only $1 \mathrm{~s}$ in liquid nitrogen, as shown in Fig. 5a, b. It was quite difficult to extract the gastrointestinal tract intact, hence female grasshoppers were selected, since their body is greater compared to the male ones. The extracted tissue was shock frozen in liquid nitrogen and stored in a $-80{ }^{\circ} \mathrm{C}$ freezer until further analysis. A single grasshopper gastrointestinal tract was mounted with a droplet of phosphate-buffered saline (PBS) on the sample holder in a CM 1860 cryostat (Leica Biosystems, Nussloch, Germany). Twelve micrometers thick sections were cut at $-21{ }^{\circ} \mathrm{C}$ and thaw-mounted on conductive ITO-coated glass slides. Between one and two sections were placed on a single ITOcoated glass slide and stored in a desiccator for approximately $1 \mathrm{~h}$. LDI-TOF MSI experiments of the gastrointestinal tract of a grasshopper were performed in positive ion mode with $50 \mu \mathrm{m}$ spatial resolution and within a mass range of $\mathrm{m} / \mathrm{z} 0$ to 1000.

Excrements One-day-old feces were stored at room temperature in a glass vial until further analysis the next day. The feces were embedded in gelatin $(10 \% \mathrm{w} / \mathrm{v})$ using a disposable specimen mold (Ø 22 mm, Plano GmbH, Wetzlar, Germany), as shown in Fig. 6a. Twelve micrometers thick sections were cut in a cryostat using a temperature of $-21^{\circ} \mathrm{C}$ (see Fig. 6b) and thaw-mounted on conductive ITO-coated glass slides. One section was fitting on one ITO-coated glass slide and was stored in a desiccator for approximately $1 \mathrm{~h}$. LDI-TOF MSI experiments on grasshopper feces were performed in positive ion mode with $60 \mu \mathrm{m}$ spatial resolution and within a mass range of $m / z, 200$ to 1500 .

Grass leaves/grasshoppers/excrements All MSI experiments were performed on a UltrafleXtreme MALDI-TOF/ TOF mass spectrometer (Bruker Daltonik $\mathrm{GmbH}$ ) equipped with a smartbeam ${ }^{\mathrm{TM}}$ II laser. Each measurement was precalibrated externally using a commercial peptide calibration mixture (Bruker Daltonik GmbH) spotted on the same ITOcoated glass slide as the tissue at multiple positions. Subsequently, the measured datasets were visualized and partly analyzed using the software packages FlexImaging 4.0 (Bruker Daltonik GmbH) and SCiLS Lab 2015b (SCiLS GmbH, Bremen, Germany).

Water extractable soil organic matter (SOM) Ten grams of homogenized fresh soil sample from 0 to $4 \mathrm{~cm}$ soil depth of the control and the grasshopper mesocosms was each weighted into a $45-\mathrm{mL}$ centrifuge tube. Thirty milliliters of deionized water was added and horizontally shaken for $2 \mathrm{~h}$ at $150 \mathrm{rpm} /$ $\min$. After $5 \mathrm{~min}$ of centrifugation at $2800 \times \mathrm{g}$, the solutions were filtered under vacuum $(0.45 \mu \mathrm{m}$ pore size, cellulose acetate filter, Sartorius, Göttingen, Germany) and the resulting extracts were freeze-dried immediately. Subsequently, the extracts were re-suspended in $500 \mu \mathrm{L}$ methanol and $1 \mu \mathrm{L}$ was spotted on a MTP 384 target plate ground steel BC (Bruker Daltonik). The LDI-TOF MS experiments were performed as well on an UltrafleXtreme MALDI-TOF/TOF mass spectrometer in the positive ion mode within a mass range of $m / z, 150$ to 2000. The resulting mass spectra are presented in Fig. 7.

Identification of secondary plant metabolites All studied compartments, including grass, chewed grass (grass leaves containing grasshopper bites), grasshopper bodies, grasshopper excrements, topsoil $(0$ to $4 \mathrm{~cm}$ soil depth, root-free) of control and grasshopper mesocosms, were freeze-dried and carefully ground with a mixer mill (MM 200, Retsch, Haan, Germany) at room temperature and, subsequently, a $10 \mathrm{mg} / \mathrm{mL}$ methanol extract prepared. One microliter of the resulting extract was spotted on a MTP 384 target plate ground steel BC (Bruker Daltonik GmbH). All LDI-TOF MS and MS/MS experiments were performed on an UltrafleXtreme or Ultraflex III MALDI TOF/TOF mass spectrometer (Bruker Daltonik GmbH), operating in the positive or negative ion mode, employing argon at a pressure of 2.5 bar as collision gas in the MS/MS mode. The resulting MS/MS spectra were compared with the ones obtained from the reference standards to proof the identities of the secondary plant metabolites.

Additionally, $20 \mathrm{mg} / \mathrm{mL}$ methanol extracts was prepared from the studied compartments and analyzed by liquid-chromatography mass spectrometry (LC-MS) following a method described elsewhere [28]. In detail, the LC analysis was conducted on an Agilent 1100 Series LC system (Santa Clara, CA, USA) using a reversed phase column (EC 250/4.6 Nucleodur Sphinx, RP $5 \mu \mathrm{m}$, Macherey-Nagel, Düren, Germany). The solvent system comprised of $0.2 \%$ aqueous formic acid and acetonitrile using at flow rate of $1 \mathrm{~mL} / \mathrm{min}$ at a temperature of $25^{\circ} \mathrm{C}$. The proportion of acetonitrile was increased from 10 to $50 \%$ in a linear gradient of 20 min followed by an increase to $75 \%$ in another $5 \mathrm{~min}$. After the column was washed for 2 min with $100 \%$ acetonitrile, it was reequilibrated to the initial eluent composition for $4 \mathrm{~min}$ prior to the next analysis. Mass spectra were recorded using an Esquire 6000 ESI-ion trap mass spectrometer (Bruker Daltonik GmbH). Typically, the secondary plant metabolites were analyzed in negative ion mode with a skimmer voltage of $60 \mathrm{~V}$, a capillary exit voltage of $-121 \mathrm{~V}$, and a capillary voltage of $4000 \mathrm{~V}$. Nitrogen was used as drying gas $\left(11 \mathrm{~mL} / \mathrm{L}, 330{ }^{\circ} \mathrm{C}\right)$ as well as nebulizer gas (pressure $35 \mathrm{psi}$ ). The secondary plant metabolites were identified by mass spectral data and chromatographic retention times in comparison to the reference standards. 


\section{Results and discussion}

\section{MALDI-TOF MSI analysis of a grass leaf}

Method development First, the MSI experiments were conducted with no matrix application in both, the positive and negative ion mode. However, the low number of detected signals led us to the conclusion that a matrix is required to increase the number of detectable ions. Hence, the common two matrices $\alpha$-CHCA and DHB [9] were evaluated for the MALDI-TOF MSI analysis on grass leave surfaces. DHB $(150 \mathrm{mg} / \mathrm{mL}$ in $50 \%$ methanol) sprayed with an air-brush device gave the highest number of detectable peaks in the positive ion mode and was therefore explored in more detail. It should be noted that the uneven leaf surface resulted in a mass variation of up to $m / z \pm 1$, thus the shown ion images in Fig. 2 are generated using a mass window of up to $\mathrm{m} / \mathrm{z} \pm 1$. To overcome this phenomenon, it is possible on the one hand to use a lock mass [29], or on the other hand to employ a newly developed recalibration software [30]; however, both approaches lie beyond the scope of this study. In order to prove that no interfering signals are present in the MALDI-TOF MSI dataset, two regions within the plant leaf were selected and total-ion-current (TIC) spectra constructed, as presented in the Electronic Supplementary Material (ESM) Fig. S3.

Plant response to insect herbivory Polyphenols, which are produced by plants as a defense against aboveground herbivory [31], consist among others of simple phenols, phenolic acids, and flavonoids. All these compounds are readily soluble in methanol [32], hence a 50\% methanol solution was used for the preparation of the matrix solution, so that we could assume to detect in particular polyphenols on the grass leaves with this method. We additionally analyzed the secondary metabolite standards (3-dehydroquinic acid, quinic acid, apigenin, luteolin, tricin, and rosmarinic acid) with DHB as matrix in the positive ion mode to prove their detection. The corresponding mass spectra can be found in the ESM Fig. S2.

As mentioned in the introduction, the question, which we would like to answer with the MALDI-TOF MSI experiments of grass leaves exposed to grasshoppers, is: Is it possible to visualize the response of herbivore feeding and mechanical damage of the grass leaves? Two kinds of reactions are likely: a rapidly propagating response throughout the plant or a response restricted to the wound site [33]. In our case, we observed the reduction of the concentration of certain compounds next to the wound, if a mechanical damage was performed shortly before the application of a matrix (see insert of Fig. 2a, b), and otherwise a nearly homogeneous distribution of defense compounds (see Fig. 2c-e). The mechanical damage (the area of the mechanical damage is denoted with a black square in Fig. 2b) caused a disruption of the cuticula of the leaf and the underlying secondary metabolites, such as quinic acid, apigenin, and luteolin, were presumably be oxidized leading to a decrease next to the wounded area. In two cases (Fig. 2b, f), a natural physiological gradient of the secondary metabolites is obtained. However, the secondary plant metabolites are already present in the leaves before the grasshopper attack, as measured by LDI-TOF MS analysis of ground grass leaves (see Table 2). A duration of 1 day between the feeding by grasshoppers and the subsequent analysis was selected in order to monitor the metabolic changes, which start after several hours and are still in progress after 1 day [34]. Since no increase of secondary plant metabolites next to the grasshopper bites are obtained, it is assumed that the time point of 1 day is maybe too short and the metabolic changes will only be visible to a later point in time [35].

Identification The putative identification of the recorded secondary plant metabolites by on-tissue tandem MS analysis did not generate any useful data presumably due to the low sensitivity of this approach. Hence, putative secondary metabolite identities were assigned using MS/MS on the methanol extract of ground grass leaves and compared with reference standards. The MS and MS/MS spectra of the reference standards are presented in the ESM and the diagnostic ions are summarized in Table 1. The results generated from the methanol extract of grounded grass leaves are highlighted in Figs. 3 and 4, respectively. The identification of quinic acid, apigenin, luteolin, tricin, and rosmarinic acid was readily performed in both, the negative and positive ion mode. Both ion modes revealed diagnostic ions (see Table 1), which enabled the identification of the secondary plant metabolites, except of tricin, where no good mass accuracy could be observed. However, the glycosylated form of tricin was readily identified by LCMS, as described later in this manuscript.

\section{LDI-TOF MSI of a grasshopper}

Method development Preliminary data were obtained by testing a variety of different matrices typically employed for the MALDI-TOF MSI analysis of metabolites [6], such as DHB, dithranol, and 1,5-DAN in the positive and negative reflector mode, respectively. However, only the simplest sample preparation by leaving out the matrix application enabled us to use a spatial resolution of $50 \mu \mathrm{m}$, additionally, this technique prevented the delocalization of the studied compounds, which was observed, in particular when DHB was sprayed with an air-brush device on top of the grasshopper longitudinal section. The grasshopper longitudinal section was not further investigated in the current study, since it was impossible to track the secondary plant metabolites in the sections. Hence, further analysis was conducted on the extracted gastrointestinal tract. 
Table 1 Summary of diagnostic ions generated by LDI-TOF MS/MS analysis of reference standards. The corresponding spectra can be found in the ESM along with the structures of the secondary plant metabolites

\begin{tabular}{|c|c|c|c|c|c|}
\hline \multirow[t]{2}{*}{ Reference standard } & \multirow[t]{2}{*}{ Molecular formula } & \multicolumn{2}{|l|}{ Negative ion mode } & \multicolumn{2}{|l|}{ Positive ion mode } \\
\hline & & Detected ion $(\mathrm{m} / \mathrm{z})$ & Main fragment ions & Detected ion $(\mathrm{m} / \mathrm{z})$ & Main fragment ions \\
\hline 3-Dehydroquinic acid & $\mathrm{C}_{7} \mathrm{H}_{10} \mathrm{O}_{6}$ & {$[\mathrm{M}-\mathrm{H}]^{-} 189$} & $169,125,85$ & {$[\mathrm{M}+\mathrm{Na}]^{+} 213$} & $211,193,180,154,124$ \\
\hline Quinic acid & $\mathrm{C}_{7} \mathrm{H}_{12} \mathrm{O}_{6}$ & {$[\mathrm{M}-\mathrm{H}]^{-} 191$} & $171,125,83$ & {$[\mathrm{M}+\mathrm{Na}]^{+} 215$} & $213,211,193,180,154,124$ \\
\hline Apigenin & $\mathrm{C}_{15} \mathrm{H}_{10} \mathrm{O}_{5}$ & {$[\mathrm{M}-\mathrm{H}]^{-} 269$} & $225,201,151$ & {$[\mathrm{M}+\mathrm{H}]^{+} 271$} & $271,152,118$ \\
\hline Luteolin & $\mathrm{C}_{15} \mathrm{H}_{10} \mathrm{O}_{6}$ & {$[\mathrm{M}-\mathrm{H}]^{-} 285$} & $241,217,199,175,151,134$ & {$[\mathrm{M}+\mathrm{Na}]^{+} 309$} & $279,250,97,68$ \\
\hline Tricin $^{\mathrm{a}}$ & $\mathrm{C}_{17} \mathrm{H}_{14} \mathrm{O}_{7}$ & {$[\mathrm{M}-\mathrm{H}]^{-} 329$} & $314,298,284,150$ & {$[\mathrm{M}+\mathrm{H}]^{+} 331$} & $315,301,286,270,239,178,153$ \\
\hline Rosmarinic acid & $\mathrm{C}_{18} \mathrm{H}_{16} \mathrm{O}_{8}$ & {$[\mathrm{M}-\mathrm{H}]^{-} 359$} & $271,197,179,161,134$ & {$[\mathrm{M}+\mathrm{Na}]^{+} 383$} & $381,363,337,307,219,201,183$ \\
\hline
\end{tabular}

${ }^{a}$ Tricin is an in-source decay (ISD) product of the reference standard tricin-5-glycoside. Due to deviation in the mass accuracy, it is not considered as tentatively identified by LDI-TOF MS/MS

Gastrointestinal tract The gastrointestinal tract was extracted from a grasshopper body that was emerged for only $1 \mathrm{~s}$ in liquid nitrogen, as shown in Fig. 5a, b to study the route of the eaten grass leaves and with it the studied polyol and phenolic compounds in the grasshopper. Since the complete gastrointestinal tract was not embedded in an appropriate embedding medium, some organs are squeezed and displaced, as shown in Fig. 5c, d. Therefore, only the organs, which could be assigned confidently, are marked in Fig. $5 \mathrm{c}$. The ion images of dehydroquinic acid $\left(\mathrm{m} / \mathrm{z}, 213,[\mathrm{M}+\mathrm{Na}]^{+}\right.$, red color) and quinic acid $\left(\mathrm{m} / \mathrm{z}, 215,[\mathrm{M}+\mathrm{Na}]^{+}\right.$, green color $)$are overlaid on the optical image as presented in panels $\mathrm{c}$ and $\mathrm{d}$ of Fig. 5, respectively. To show the signal intensities of the MSIrelated signals and the background, two regions within the gastrointestinal tract were selected and TIC spectra constructed, as presented in the ESM Fig. S11. Except for the crop, only noise could be recorded in the other organs of the grasshopper. Dehydroquinic acid is an in-source-decay (ISD) product of quinic acid, since it can be detected measuring the reference standard quinic acid. To confirm that the reference standard quinic acid is not degraded, resulting in the formation of dehydroquinic acid, a proton nuclear magnetic resonance $\left({ }^{1} \mathrm{H}\right.$ NMR) spectrum was recorded depicting all required protons in the molecule. The corresponding ${ }^{1} \mathrm{H}$ NMR spectrum can be found in the ESM Fig. S10. Both secondary plant metabolites, dehydroquinic acid and quinic acid, can only be detected in the crop of the grasshopper, which is filled with chewed grass leaves.

The four remaining phenolic compounds, apigenin, luteolin, tricin, and rosmarinic acid, could not be detected in the crop, since they are presumably already digested in the crop. The identification of dehydroquinic acid and quinic acid was performed by MS/MS analysis on methanol extracts of ground grasshoppers and compared to the corresponding MS/ MS spectra generated from the reference standards (see ESM and Table 1). The MS and MS/MS experiments on methanol extracts of the grasshoppers were performed in both, the negative and positive ion mode, as summarized in Table 2. In the negative ion mode, apigenin and luteolin and no dehydroquinic acid and quinic acid could be detected. However, in the positive ion mode dehydroquinic acid and luteolin could be identified. The results from the negative and positive ion mode do not completely agree, highlighting the importance of the selected ion mode. The observed difference might originate from the diverse sensitivity of the ions in the corresponding ion mode.

The post-digestive effects of polyphenols usually occur in the midgut of insects through oxidative mechanisms, resulting in the formation of superoxide radicals and other reactive oxygen species [36]. The question, which is coming up is, do the considered metabolites really digest and, with this, provide the required energy for the grasshopper, or do they stay undigested and hence, can be found in the excrements. To answer this question, the excrements of the grasshoppers were analyzed by LDI-TOF MSI.

\section{LDI-TOF MSI of grasshopper excrements}

Method development The considered secondary plant metabolites (quinic acid, apigenin, luteolin, tricin, and rosmarinic acid) were detectable in the grass leaf and partially as well in the grasshopper employing the positive ion mode, hence this mode was furthermore used for the analysis of excrements. The matrix DHB was sprayed with an air-brush device on top of the excrements or as alternative no matrix was used. The LDI-TOF MSI analysis will be considered here in detail, since the number of detectable signals was higher than the ones obtained for the MALDI-TOF MSI analysis using DHB as matrix.

Undigested plant metabolites in excrements The collected excrements were embedded in $10 \%$ gelatin and placed in a disposable specimen mold, as shown in Fig. 6a. Afterwards, the frozen and embedded excrements were attached to the 


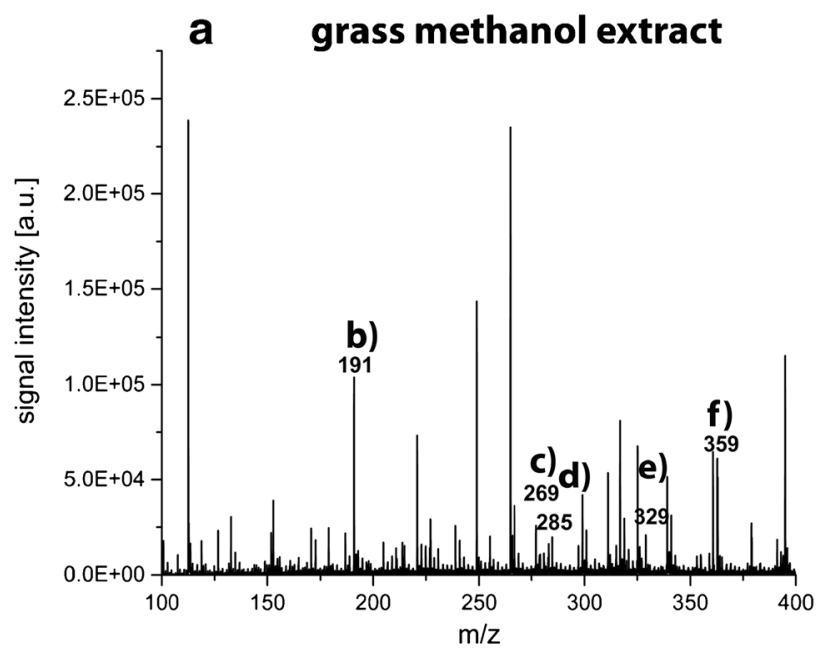

b quinic acid

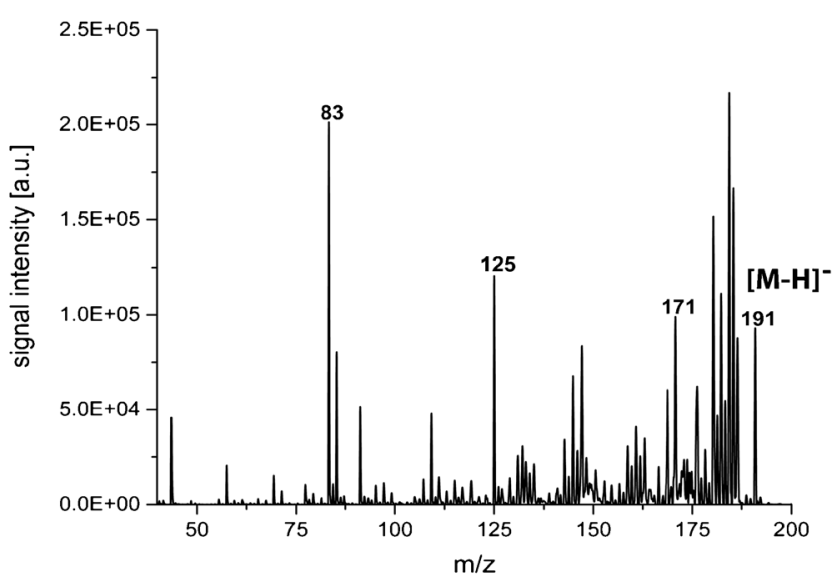

C apigenin
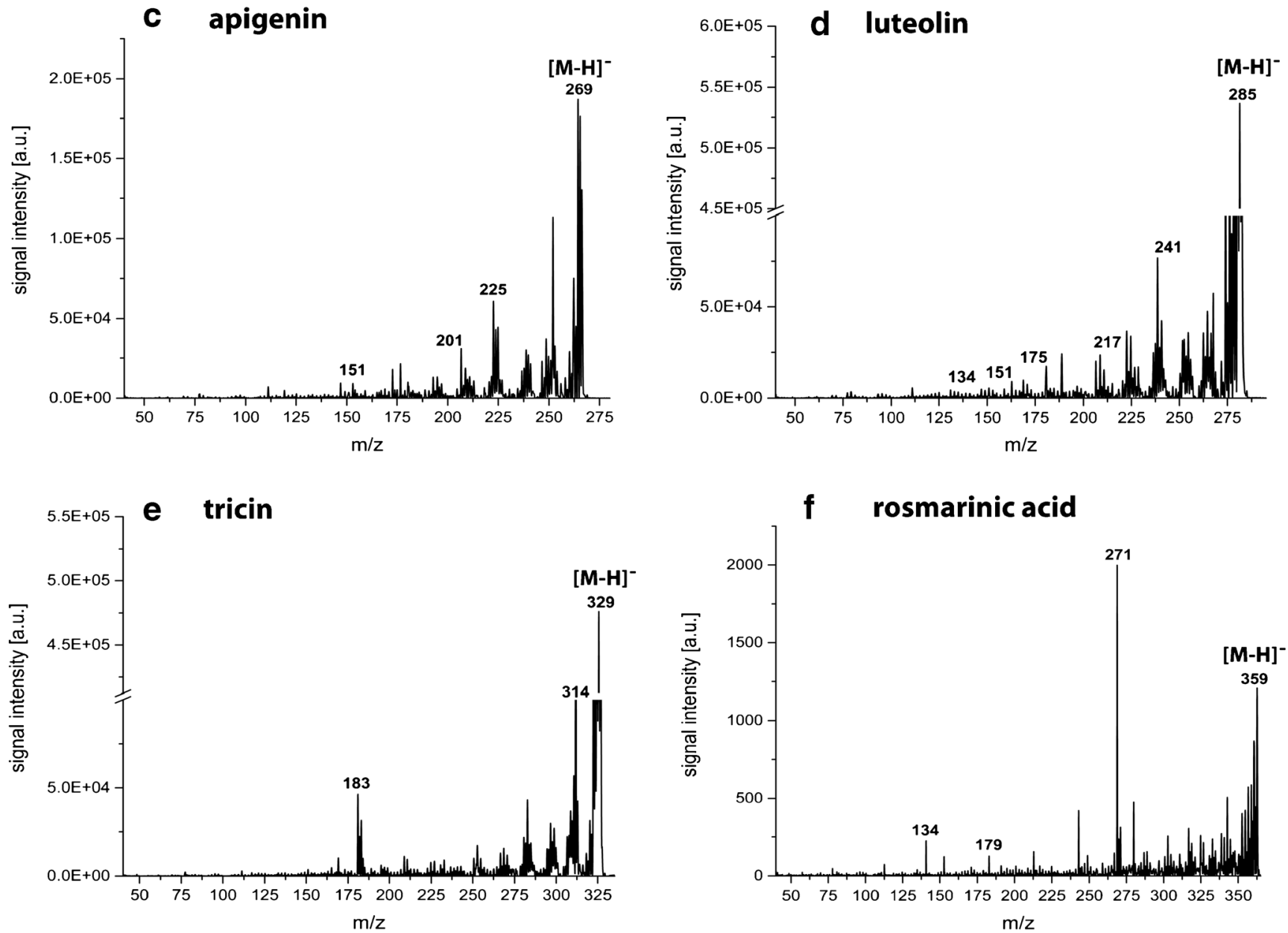

Fig. 3 LDI-TOF MS and MS/MS spectra of a methanol extract from D. glomerata leaves in the negative ion mode for the identification of the secondary metabolites monitored in the ion images in Fig. 2. The MS/

MS spectra of $\mathbf{b}$ quinic acid; $\mathbf{c}$ apigenin; $\mathbf{d}$ luteolin; $\mathbf{e}$ tricin; and $\mathbf{f}$ rosmarinic acid show the same diagnostic ions as for the reference substances summarized in Table 1

specimen disc and mounted onto the object head in a cryostat, as presented in Fig. 6b. The subsequent LDI-TOF MSI analysis of a square $(1 \mathrm{~cm} \times 1 \mathrm{~cm})$ of a $12-\mu \mathrm{m}$-thick section revealed only the presence of dehydroquinic acid and quinic

acid in the excrements. The signal intensities of the MSIrelated signals and the background from two selected regions within the excrements section is presented in the ESM in Fig. S12. In region 1 only, the signals of dehydroquinic acid 

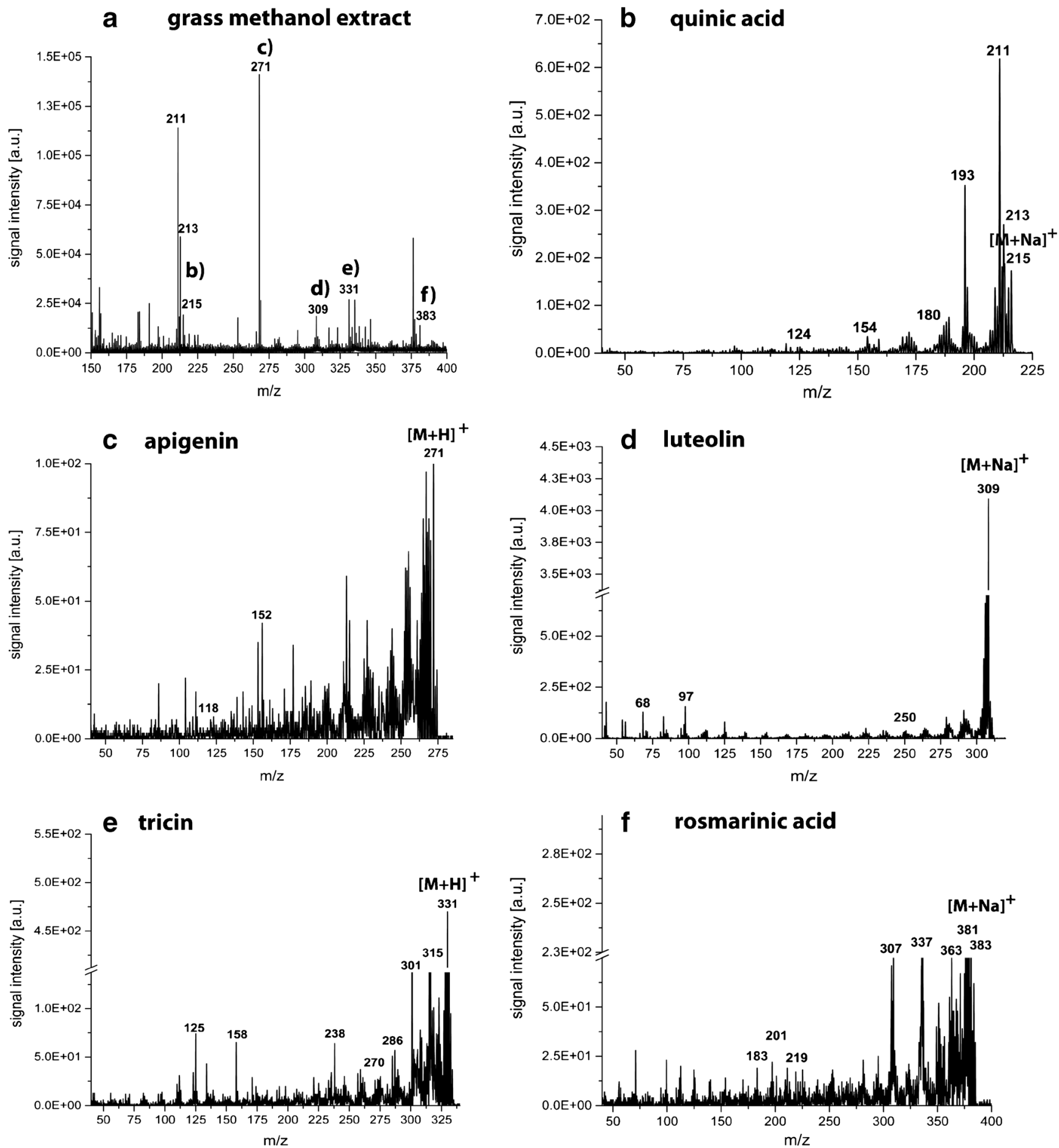

Fig. 4 LDI-TOF MS and MS/MS spectra of a methanol extract from D. glomerata leaves in the positive ion mode for the identification of the secondary metabolites monitored in the ion images in Fig. 2. The ion images in Fig. 2 were as well recorded in the positive ion mode.

and quinic acid are visible in the constructed TIC spectrum, whereas in region 2 strong signals between $\mathrm{m} / \mathrm{z}, 400$ and 600 are observed and no signals of the two considered secondary metabolites. This proves the partially presence of dehydroquinic acid and quinic acid in the analyzed excrement
The MS/MS spectra of $\mathbf{b}$ quinic acid; $\mathbf{c}$ apigenin; $\mathbf{d}$ luteolin; e tricin; and $\mathbf{f}$ rosmarinic acid show the same diagnostic ions as for the reference substances summarized in Table 1

section, as shown in panel c and d of Fig. 6, respectively. The identification of both metabolites was as well confirmed by MS/MS (see Table 2), as described previously, and compared with the data obtained from the reference standards (see ESM and Table 1). The analysis of the methanol extracts of the 
Fig. 5 LDI-TOF MSI analysis of the gastrointestinal tract of a female $C$. dorsatus. The photographs show a the fixation of the partly frozen animal, and $\mathbf{b}$ the halfway extracted gastrointestinal tract. Ion images from the LDI-TOF MSI analysis present the distribution of $\mathbf{c}$ dehydroquinic acid $(\mathrm{m} / \mathrm{z}, 213$, [M+ $\mathrm{Na}]^{+}$, red color) and $\mathbf{d}$ quinic acid $\left(\mathrm{m} / \mathrm{z}, 215,[\mathrm{M}+\mathrm{Na}]^{+}\right.$, green color $)$, overlaid on the optical image taken before MSI

Note: The assignments of the secondary plant metabolites are tentative based on MS and MS/ MS experiments of methanol extracts of $C$. dorsatus, as summarized in Table 2 and compared with reference standards, as presented in the ESM. The ion images are normalized using the TIC. Scale bar $1000 \mu \mathrm{m}$ (d)
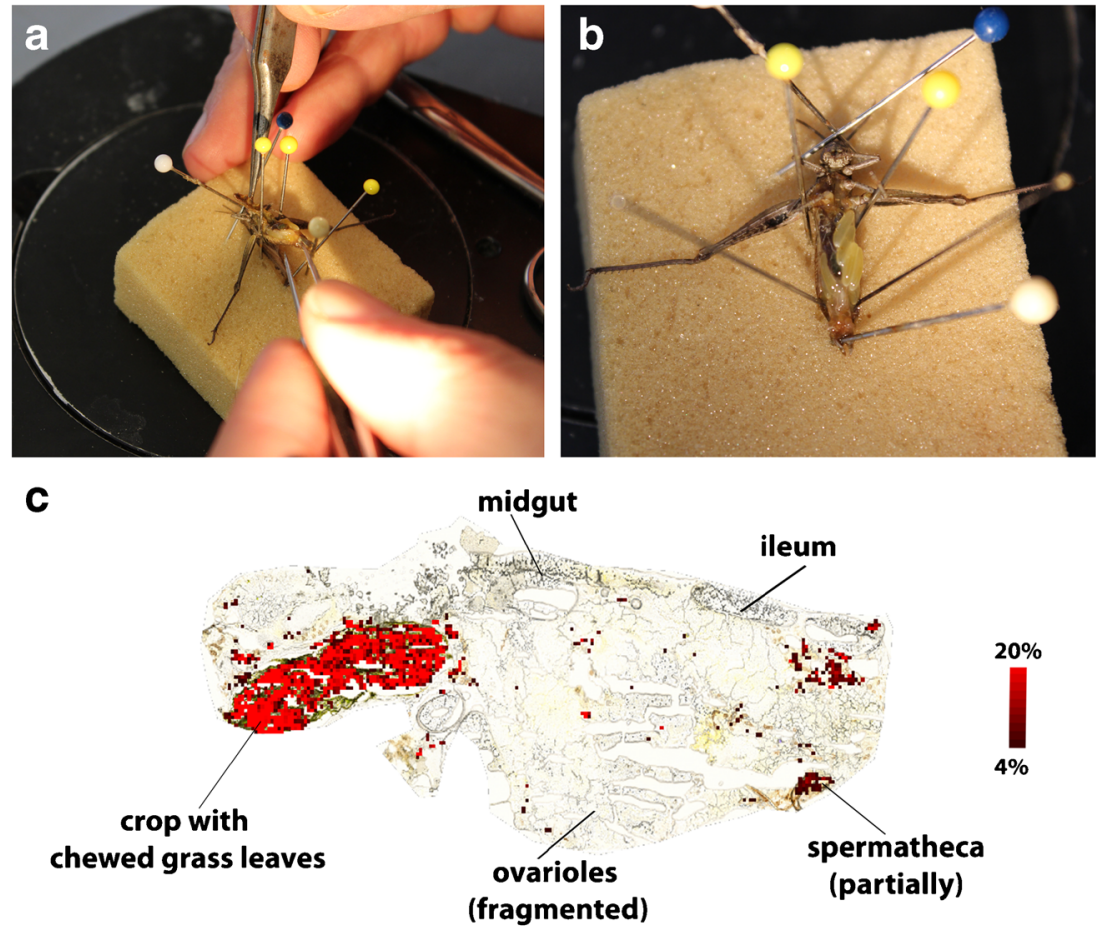

d

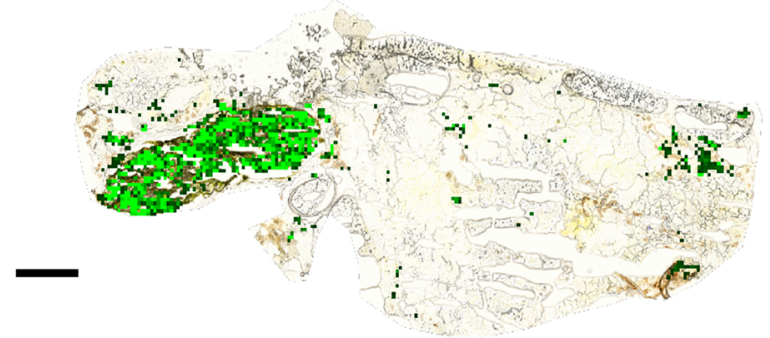

$20 \%$

viewed in panels $\mathrm{c}$ and $\mathrm{d}$ of Fig. 6, respectively. It can be concluded from Fig. 6 that only the cyclic polyol compounds remain undigested by the grasshoppers and are released while the other four investigated phenolic compounds are maybe used to gain energy or to form reactive oxygen species.

\section{LDI-TOF MS of soil organic matter}

Presence of secondary plant metabolites in water extractable SOM The answer, which is still missing is, if these cyclic polyols finally enter the soil via rapid leaching of excrements or not. As shown in Fig. 7, dehydroquinic acid with an $\mathrm{m} / \mathrm{z}$ value of $213[\mathrm{M}+\mathrm{Na}]^{+}$and quinic acid with an $\mathrm{m} / z$ value of $215[\mathrm{M}+\mathrm{Na}]^{+}$are readily visible as compounds of water extractable SOM in both control and grasshopper mesocosms. The assignment of the signals was performed by MS/MS analysis and diagnostic ions from the spectra correspond to the ones obtained from the reference standards (summarized in Table 1). Hence, dehydroquinic acid and quinic acid can not only enter the soil as leachates from excrements but also from the grass leaves itself as decomposition products [37].
The obtained ion images of dehydroquinic acid and quinic acid overlaid on the optical image acquired prior MSI can be 


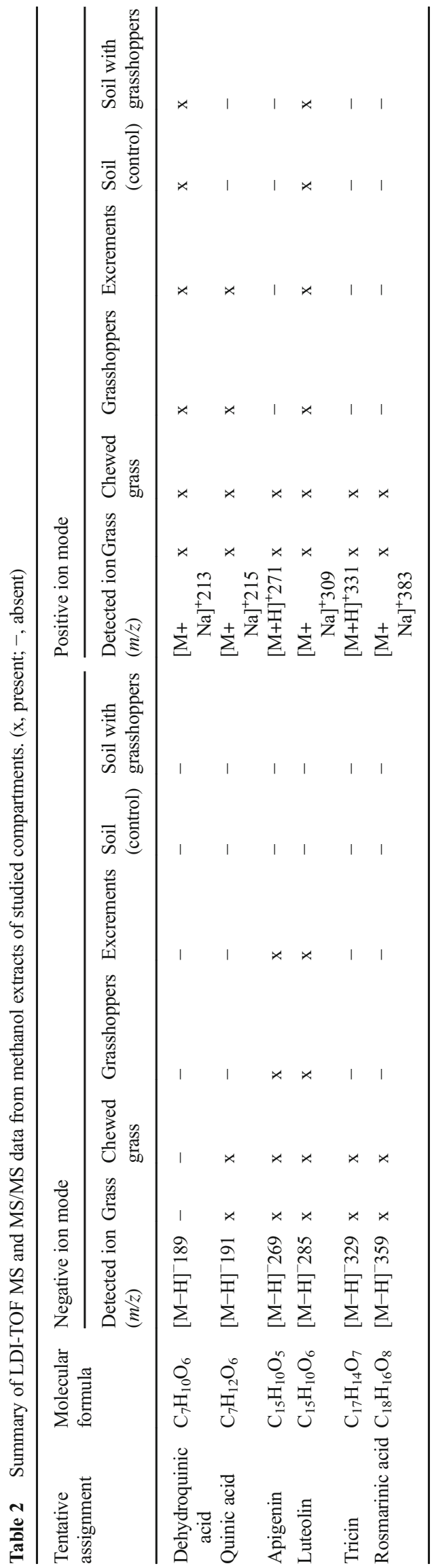

Presence of secondary plant metabolites in methanol extractable SOM The last answer, which needs to be addressed is, if the cyclic polyol compounds detected in the organic substances of the soil solution can also be found in the more stable SOM matter pool of both soil samples of control and grasshopper mesocosms. In order to approach this last step, a methanol extract of the topsoil ( $0-4 \mathrm{~cm}$ soil depth) sampled from the mesocosms was prepared and the resulting LDI-TOF MS spectra are presented in Fig. 8. The recorded spectra in Fig. 8 are more complex, than the ones recorded in Fig. 7, since Fig. 8 considers the bulk soil samples and not only the water extractable part. Dehydroquinic acid with an $m / z$ value of $213[\mathrm{M}+\mathrm{Na}]^{+}$, and luteolin with an $\mathrm{m} / \mathrm{z}$ value of $309[\mathrm{M}+$ $\mathrm{Na}^{+}$, are readily visible in both topsoil materials, whereas the three remaining secondary plant metabolites (apigenin, tricin, and rosmarinic acid) cannot be detected, since they have likely been converted in the grasshoppers body or formed insoluble complexes with soil proteins [20]. The MS/MS experiments from dehydroquinic acid and luteolin confirm the presence of both secondary plant metabolites. In comparison with LDITOF MS of water extractable SOM, quinic acid is not present in the bulk soil, since it is presumably completely converted to dehydroquinic acid, as an ISD product. However, this secondary plant metabolite is only detectable in the positive ion mode. In summary, dehydroquinic acid can also be found in the bulk soil samples, independently from herbivory (see Table 2).

\section{LC-MS analysis of methanol extracts of the studied compartments}

From the studied compartments, including grass leaves, chewed grass leaves, grasshoppers, excrements, soil of control and grasshopper mesocosms, methanol extracts of the grounded material were prepared and subsequently analyzed by LCMS. The obtained results are summarized in Table 3. Besides quinic acid, derivatives of the acid are detected in LC-MS, such as caffeoyl quinate and ferroyl quinate. Both compounds are not detectable with LDI-TOF MS, however the signal of quinic acid comes partly from them. To proof this hypothesis, the derivative cryptochlorgenic acid was purchased and analyzed by LDI-TOF MS. (Since the derivatives caffeoyl quinate and ferroyl quinate were unavailable, cryptochlorgenic acid was used instead.) In the recorded mass spectrum, a signal originating from quinic acid was obtained, which was formed as an ISD product from cryptochlorgenic acid. The same case was obtained for the polyphenols apigenin, luteolin, and tricin. Here, only the glycosylated forms can be detected with LC-MS. Since only the 5glycoside forms were purchasable, they were used to show that these derivatives show in LDI-TOF MS a signal for the pure polyphenol without the sugar moiety. Hence, it can be concluded that apigenin, luteolin, and tricin are unsuitable 

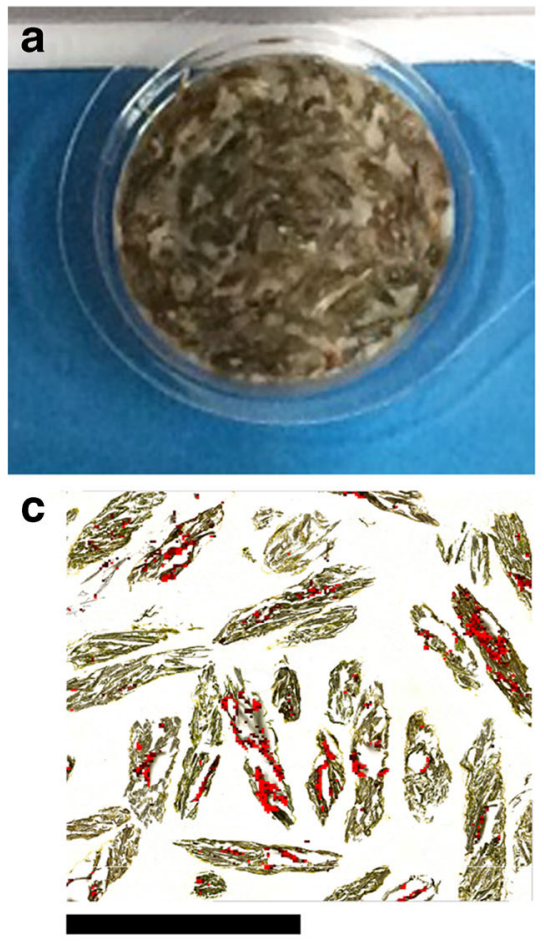

$4 \%$

$20 \%$

Fig. 6 LDI-TOF MSI analysis of excrements of $C$. dorsatus. The photographs show a excrements embedded in $10 \%$ gelatin in a disposable specimen mold; $\mathbf{b}$ view into the cryostat where the embedded excrements are attached with BPS onto the specimen disc, which is mounted on the object head. The ion images generated by LDI-TOF MS of dehydroquinic acid $(\mathrm{m} / \mathrm{z}$ $213,[\mathrm{M}+\mathrm{Na}]^{+}$, red color $)$and quinic acid $\left(\mathrm{m} / z 215,[\mathrm{M}+\mathrm{Na}]^{+}\right.$, green color $)$ are overlaid on the optical image in picture $\mathbf{c}$ and $\mathbf{d}$, respectively

biomarkers to trace DOM, since they are formed as ISD products from the glycosylated structures.

The LC-MS data highlight the presence of the following secondary metabolites in both compartments grass and chewed grass: quinic acid, caffeoyl quinate, ferroyl quinate, tricin-hexoside, rosmarinic acid, apigenin-hexosidepentoside, and luteolin-hexoside-pentoside. Using the LCMS data to validate the MSI data, as summarized in Table 4, it can be concluded that the MSI data show the same-targeted secondary compounds present in the leaf, as the LC-MS data, taking into account that ISD products of quinic acid, tricin, apigenin, and luteolin were formed by LDI-TOF MSI. Furthermore, apigenin-hexoside-pentoside and luteolinhexoside-pentoside could be detected up to the grasshoppers' excrements by LC-MS analysis. Hence, one would expect to detect apigenin and luteolin in the grasshopper crop and excrements by LDI-TOF MSI. However, this is not the case. Only quinic acid and its ISD product dehydroquinic acid could be determined by MSI. One suitable explanation is the presumably higher sensitivity of the glycosylated forms of apigenin and luteolin by LC-MS analysis compared to the non-glycosylated forms by the imaging technique LDI-TOF MSI. By preparing a $\mathrm{MeOH}$ extract from a scrapped off

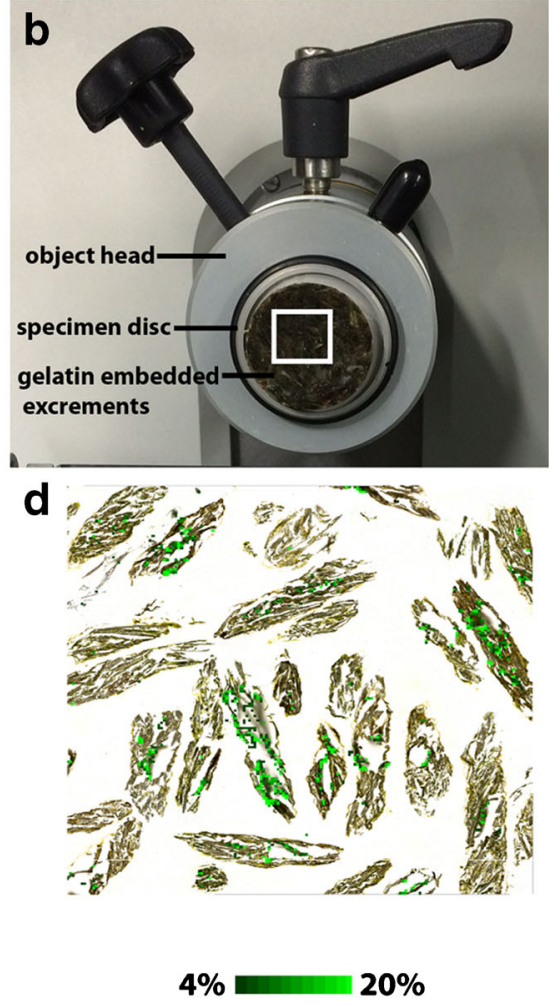

Note: The assignments of the secondary plant metabolites are tentative based on MS and MS/MS experiments of methanol extracts of the excrements, as summarized in Table 2 and compared with reference standards, as presented in the ESM. The ion images are normalized using the TIC. Scale bar $5 \mathrm{~mm}(\mathbf{c})$

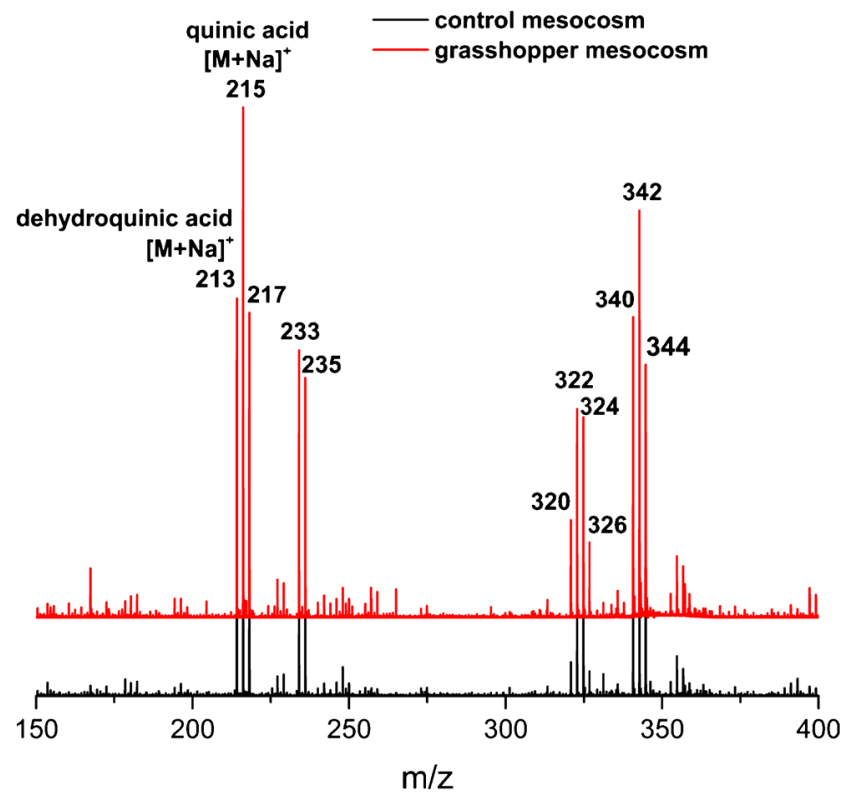

Fig. 7 LDI-TOF MS analysis of water extractable SOM in both, control (black line color) and grasshopper (red line color) mesocosms in the positive ion mode. The secondary plant metabolites dehydroquinic acid $\left(\mathrm{m} / \mathrm{z}, 213,[\mathrm{M}+\mathrm{Na}]^{+}\right)$and quinic acid $\left(\mathrm{m} / \mathrm{z}, 215,[\mathrm{M}+\mathrm{Na}]^{+}\right)$are readily visible in both mesocosms and were putative assigned by MS/MS analysis 


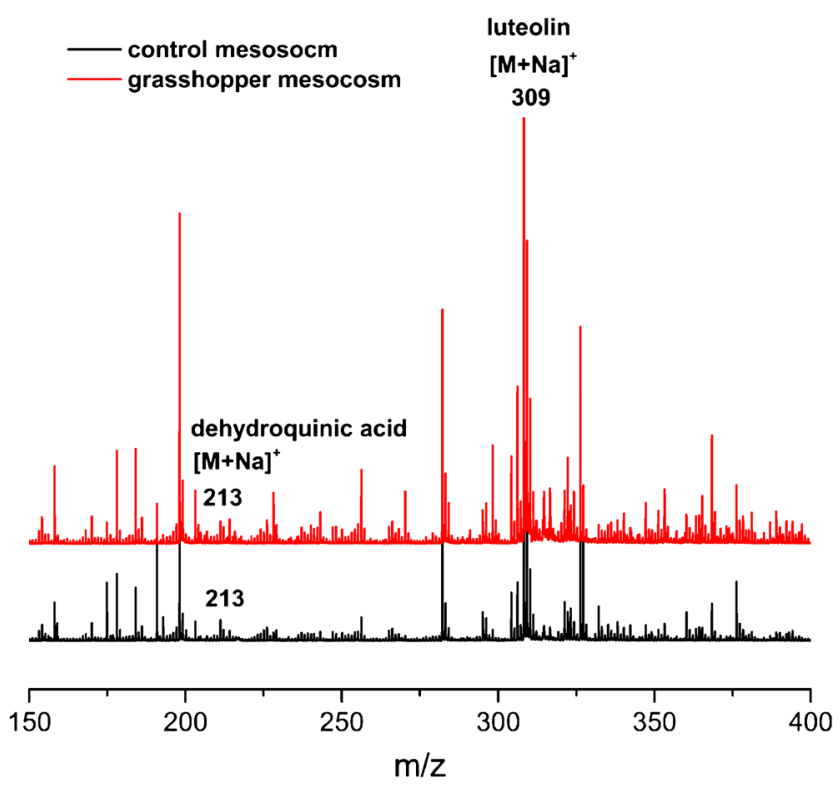

Fig. 8 LDI-TOF MS analysis of methanol extractable SOM in both, control (black line color) and grasshopper (red line color) mesocosms in the positive ion mode. The secondary plant metabolites dehydroquinic acid $\left(\mathrm{m} / \mathrm{z}, 213,[\mathrm{M}+\mathrm{Na}]^{+}\right)$and luteolin $\left(\mathrm{m} / z, 309,[\mathrm{M}+\mathrm{Na}]^{+}\right)$are readily visible in both mesocosms and were putative assigned by MS/MS analysis

excrement slice, one could detect luteolin by LDI-TOF MS, underlining the sensitivity differences between MSI and solution-based MS, as described early in this manuscript.
Surprisingly are the strong signals originating from quinic acid and its ISD product dehydroquinic acid by LDI-TOF MSI in the positive ion mode. The easy ionization of this secondary plant metabolite by LDI in the positive ion mode might be one reason of its appearance throughout all compartments. Indeed, in the negative ion mode, dehydroquinic acid is not measurable in any compartment by LDI-TOF MS (see Table 2); moreover, quinic acid is only detectable in the control and chewed grass highlighting the differential ionization efficiency of the two considered secondary plant metabolites in the diverse ion modes.

\section{Conclusion}

In summary, the present study demonstrated the implementation of the analytical techniques LDI-TOF MSI and MALDI-TOF MSI to follow the fate and transport of various secondary plant metabolites, in particular two cyclic polyols and four polyphenols. The secondary plant metabolites were traced from the grass leaves of D. glomerata, which were taken up by the grasshopper C. dorsatus, or deposited as excrements, finally ending up in the soil extracts and bulk soil. Table 4 presents a short summary of the MSI data. Only the cyclic polyols, dehydroquinic acid, which is formed from quinic acid as an ISD product, and quinic acid itself followed this route,

Table 3 Summary of LC-MS data from methanol extracts of studied compartments. (x, present; -, absent)

\begin{tabular}{|c|c|c|c|c|c|c|c|c|c|c|}
\hline Tentative assignment & $\begin{array}{l}\text { Molecular } \\
\text { formula }\end{array}$ & $\mathrm{R}_{\mathrm{t}}(\min )$ & Reference & $\begin{array}{l}\text { Detected } \\
\text { ion }(\mathrm{m} / \mathrm{z})\end{array}$ & Grass & $\begin{array}{l}\text { Chewed } \\
\text { grass }\end{array}$ & Grasshoppers & Excrements & $\begin{array}{l}\text { Soil } \\
\text { (control) }\end{array}$ & $\begin{array}{l}\text { Soil with } \\
\text { grasshoppers }\end{array}$ \\
\hline Dehydroquinic acid & $\mathrm{C}_{7} \mathrm{H}_{10} \mathrm{O}_{6}$ & & & $\begin{array}{c}{[\mathrm{M}-\mathrm{H}]^{-}} \\
189\end{array}$ & - & - & - & - & - & - \\
\hline Quinic acid & $\mathrm{C}_{7} \mathrm{H}_{12} \mathrm{O}_{6}$ & 2.8 & {$[32]$} & $\begin{array}{c}{[\mathrm{M}-\mathrm{H}]^{-}} \\
191\end{array}$ & $\mathrm{x}$ & $\mathrm{x}$ & - & - & - & - \\
\hline Caffeoyl quinate & $\mathrm{C}_{16} \mathrm{H}_{18} \mathrm{O}_{9}$ & $\begin{array}{c}3 \text { isomers } \\
\text { at } 7.3 \text {, } \\
9.1, \\
11.3\end{array}$ & [38] & $\begin{array}{c}{[\mathrm{M}-\mathrm{H}]^{-}} \\
353\end{array}$ & $\mathrm{x}$ & $\mathrm{x}$ & - & - & - & - \\
\hline Ferroyl quinate & $\mathrm{C}_{17} \mathrm{H}_{20} \mathrm{O}_{9}$ & 9.4 & [38] & $\begin{array}{c}{[\mathrm{M}-\mathrm{H}]^{-}} \\
367\end{array}$ & $\mathrm{x}$ & $\mathrm{x}$ & - & - & - & - \\
\hline Apigenin & $\mathrm{C}_{15} \mathrm{H}_{10} \mathrm{O}_{5}$ & & {$[32]$} & $\begin{array}{c}{[\mathrm{M}+\mathrm{H}]^{+}} \\
269\end{array}$ & - & - & - & - & - & - \\
\hline Apigenin-hexoside-pentoside & $\mathrm{C}_{26} \mathrm{H}_{28} \mathrm{O}_{15}$ & 10.5 & [38] & $\begin{array}{c}{[\mathrm{M}-\mathrm{H}]^{-}} \\
563\end{array}$ & $\mathrm{x}$ & $\mathrm{x}$ & $\mathrm{x}$ & $\mathrm{x}$ & - & - \\
\hline Luteolin & $\mathrm{C}_{15} \mathrm{H}_{10} \mathrm{O}_{6}$ & & {$[32]$} & $\begin{array}{c}{[\mathrm{M}-\mathrm{H}]^{-}} \\
285\end{array}$ & - & - & - & - & - & - \\
\hline Luteolin-hexoside-pentoside & $\mathrm{C}_{26} \mathrm{H}_{28} \mathrm{O}_{15}$ & 9.5 & [38] & $\begin{array}{c}{[\mathrm{M}-\mathrm{H}]^{-}} \\
579\end{array}$ & $\mathrm{x}$ & $\mathrm{x}$ & $\mathrm{x}$ & $\mathrm{x}$ & - & - \\
\hline Tricin & $\mathrm{C}_{17} \mathrm{H}_{14} \mathrm{O}_{7}$ & & [38] & $\begin{array}{c}{[\mathrm{M}+\mathrm{H}]^{-}} \\
331\end{array}$ & - & - & - & - & - & - \\
\hline Tricin-hexoside & $\mathrm{C}_{23} \mathrm{H}_{24} \mathrm{O}^{12}$ & 13.0 & [39] & $\begin{array}{c}{[\mathrm{M}-\mathrm{H}]-} \\
491\end{array}$ & $\mathrm{x}$ & $\mathrm{x}$ & - & - & - & - \\
\hline Rosmarinic acid & $\mathrm{C}_{18} \mathrm{H}_{16} \mathrm{O}_{8}$ & 15.7 & [38] & $\begin{array}{c}{[\mathrm{M}-\mathrm{H}]^{-}} \\
359\end{array}$ & $\mathrm{x}$ & $\mathrm{x}$ & - & - & - & - \\
\hline
\end{tabular}


Table 4 Summary of MSI data. (x, present; -, absent)

\begin{tabular}{llllll}
\hline $\begin{array}{l}\text { Tentative } \\
\text { assignment }\end{array}$ & $\begin{array}{l}\text { Molecular } \\
\text { formula }\end{array}$ & $\begin{array}{l}\text { Detected ion } \\
(m / z)\end{array}$ & $\begin{array}{l}\text { Chewed } \\
\text { grass }\end{array}$ & Grasshopper & Excrements \\
\hline $\begin{array}{l}\text { Dehydroquinic acid } \\
\text { Quinic acid }\end{array}$ & $\mathrm{C}_{7} \mathrm{H}_{10} \mathrm{O}_{6}$ & {$[\mathrm{M}+\mathrm{Na}]^{+} 213$} & - & $\mathrm{x}$ & $\mathrm{x}$ \\
Apigenin & $\mathrm{C}_{7} \mathrm{H}_{12} \mathrm{O}_{6}$ & {$[\mathrm{M}+\mathrm{Na}]^{+} 215$} & $\mathrm{x}$ & $\mathrm{x}$ & $\mathrm{x}$ \\
Luteolin & $\mathrm{C}_{15} \mathrm{H}_{10} \mathrm{O}_{5}$ & {$[\mathrm{M}+\mathrm{H}]^{+} 271$} & $\mathrm{x}$ & - & - \\
Tricin & $\mathrm{C}_{15} \mathrm{H}_{10} \mathrm{O}_{6}$ & {$[\mathrm{M}+\mathrm{Na}]^{+} 309$} & $\mathrm{x}$ & - & - \\
Rosmarinic acid & $\mathrm{C}_{17} \mathrm{H}_{14} \mathrm{O}_{7}$ & {$[\mathrm{M}+\mathrm{H}]^{+} 331$} & $\mathrm{x}$ & - & - \\
\hline
\end{tabular}

the four polyphenols, apigenin, luteolin, tricin, and rosmarinic acid, were not deposited as excrements. This can have several reasons: The specific polyphenols (1) can be converted in the grasshoppers' crop, (2) can be digested in the grasshoppers' midgut, (3) can form reactive superoxide species in the grasshoppers' midgut [36], or (4) can build up insoluble protein-complexes in the soil [40]. The identification of the considered secondary plant metabolites was performed on methanol extracts of the various compartments and compared with the MS/MS data generated from the corresponding reference standards, since the on-tissue MS/MS analysis was not sensitive enough. Additional LC-MS data were acquired from methanol extracts from the compartments and apigeninhexoside-pentoside and luteolin-hexoside-pentoside could be traced up to the grasshoppers' excrements in contrast to the MSI results. By tacking the LC-MS results to verify the MSI results, it became obvious that the MSI technique, although providing spatial information, which cannot be gained by LC-MS, suffered from sensitivity issues. Hence, the combination of MSI and LC-MS is the way to approach environmental questions, as described here. In conclusion, no ideal secondary plant metabolite could be found to function as a biomarker for tracing the source of DOM in soil upon insect herbivory. Even though, quinic acid, which owns a potential allelophatic role by modulating plant community composition [37], could be traced in all compartments by MSI, the LC-MS data did not proof this behavior. The comparison of both MS techniques, MSI and LC-MS, mirrors the complexity of the studied system.

Acknowledgements The authors thank Prof. Dr. G. Köhler (Friedrich Schiller University Jena, Institute of Ecology, Population Ecology) for support with the annotation of the histological image of the gastrointestinal tract of a grasshopper, the preparator M. Krüger (Phyletische Museum, Jena) who extracted the gastrointestinal tract from the grasshopper body, and Dr. M. Reichelt (Max Plank Institute for Chemical Ecology, Department of Biochemistry) for performing the LC-MS experiments. The work has been funded by the Deutsche Forschungsgemeinschaft (DFG) CRC 1076 "AquaDiva”. The Ultraflex III and UltrafleXtreme MALDI TOF/TOF mass spectrometers were purchased with grants from the Thüringer Ministerium für Bildung, Jugend und Sport (grand no. B515-07008), and Deutsche
Forschungsgemeinschaft (DFG, grand no. EG 102/4-1), respectively. Climate chambers to conduct experiments under controlled temperature conditions were financially supported by the Thüringer Ministerium für Wirtschaft, Wissenschaft und Digitale Gesellschaft (TMWWDG; project B 715-09075).

\section{Compliance with ethical standards}

Conflict of interest The authors declare that they have no competing interests.

Open Access This article is distributed under the terms of the Creative Commons Attribution 4.0 International License (http:// creativecommons.org/licenses/by/4.0/), which permits unrestricted use, distribution, and reproduction in any medium, provided you give appropriate credit to the original author(s) and the source, provide a link to the Creative Commons license, and indicate if changes were made.

\section{References}

1. Dale VH, Joyce LA, McNulty S, Neilson RP, Ayres MP, Flannigan $\mathrm{MD}$, et al. Climate change and forest disturbances. Bioscience. 2001;51(9):723-34.

2. Bale JS, Masters GJ, Hodkinson ID, Awmack C, Bezemer TM, Brown VK, et al. Herbivory in global climate change research: direct effects of rising temperature on insect herbivores. Glob Change Biol. 2002;8(1):1-16. doi:10.1046/j.1365-2486.2002.00451.x.

3. Chapman SK, Hart SC, Cobb NS, Whitham TG, Koch GW. Insect herbivory increases litter quality and decomposition: an extension of the acceleration hypothesis. Ecology. 2003;84(11):2867-76. doi: 10.1890/02-0046.

4. Lovett GM, Ruesink AE. Carbon and nitrogen mineralization from decomposing gypsy moth frass. Oecologia. 1995;104(2):133-8. doi: $10.1007 / \mathrm{bf00328577}$

5. Fang X-M, Christenson LM, Wang F-C, Zeng J-P, Chen F-S. Pine caterpillar outbreak and stand density impacts on nitrogen and phosphorus dynamics and their stoichiometry in Masson pine (Pinus massoniana) plantations in subtropical China. Can J For Res. 2016;46(5):601-9. doi:10.1139/cjfr-2015-0357.

6. Crecelius AC, Schubert US, von Eggeling F. MALDI mass spectrometric imaging meets "omics": recent advances in the fruitful marriage. Analyst. 2015;140(17):5806-20.

7. Bartels B, Svatoš A. Spatially resolved in vivo plant metabolomics by laser ablation-based mass spectrometry imaging (MSI) techniques: LDI-MSI and LAESI. Front Plant Sci. 2015;6:471. doi: 10.3389/fpls.2015.00471.

8. Boughton BA, Thinagaran D, Sarabia D, Bacic A, Roessner U. Mass spectrometry imaging for plant biology: a review. Phytochem Rev. 2016;15:445-88. doi:10.1007/s11101-0159440-2. 
9. Dong Y, Li B, Malitsky S, Rogachev I, Aharoni A, Kaftan F, et al. Sample preparation for mass spectrometry imaging of plant tissues: a review. Front Plant Sci. 2016;7:60.

10. Dong Y, Li B, Aharoni A. More than pictures: when MS imaging meets histology. Trends Plant Sci. 21(8):686-98. doi:10.1016/j. tplants.2016.04.007.

11. Holscher D, Shroff R, Knop K, Gottschaldt M, Crecelius A, Schneider B, et al. Matrix-free UV-laser desorption/ionization (LDI) mass spectrometric imaging at the single-cell level: distribution of secondary metabolites of Arabidopsis thaliana and Hypericum species. Plant J. 2009;60(5):907-18. doi:10.1111/j. 1365-313X.2009.04012.x.

12. Shroff R, Schramm K, Jeschke V, Nemes P, Vertes A, Gershenzon J, et al. Quantification of plant surface metabolites by matrix-assisted laser desorption-ionization mass spectrometry imaging: glucosinolates on Arabidopsis thaliana leaves. Plant J. 2015;81(6):961-72. doi:10.1111/tpj.12760.

13. Bhandari DR, Schott M, Römpp A, Vilcinskas A, Spengler B. Metabolite localization by atmospheric pressure high-resolution scanning microprobe matrix-assisted laser desorption/ionization mass spectrometry imaging in whole-body sections and individual organs of the rove beetle Paederus riparius. Anal Bioanal Chem. 2015;407(8):2189-201. doi:10.1007/s00216-014-8327-1.

14. Niehoff AC, Kettling H, Pirkl A, Chiang YN, Dreisewerd K, Yew JY. Analysis of drosophila lipids by matrix-assisted laser desorption/ionization mass spectrometric imaging. Anal Chem. 2014;86(22):11086-92.

15. Kaftan F, Vrkoslav V, Kynast P, Kulkarni P, Bocker S, Cvacka J, et al. Mass spectrometry imaging of surface lipids on intact Drosophila melanogaster flies. J Mass Spectrom. 2014;49(3): 223-32. doi:10.1002/jms.3331.

16. Vrkoslav V, Muck A, Cvacka J, Svatos A. MALDI imaging of neutral cuticular lipids in insects and plants. J Am Soc Mass Spectrom. 2010;21(2):220-31. doi:10.1016/j.jasms.2009.10.003.

17. Pratavieira M, da Silva Menegasso AR, Garcia AM, Dos Santos DS, Gomes PC, Malaspina O, et al. MALDI imaging analysis of neuropeptides in the Africanized honeybee (Apis mellifera) brain: effect of ontogeny. J Proteome Res. 2014;13(6):3054-64. doi:10. 1021/pr500224b.

18. Olsen LR, Hansen SH, Janfelt C. Distribution of terfenadine and its metabolites in locusts studied by desorption electrospray ionization mass spectrometry imaging. Anal Bioanal Chem. 2015;407(8): 2149-58. doi:10.1007/s00216-014-8292-8.

19. Hattenschwiler S, Vitousek PM. The role of polyphenols in terrestrial ecosystem nutrient cycling. Trends Ecol Evol. 2000;15(6): 238-43.

20. War AR, Paulraj MG, Ahmad T, Buhroo AA, Hussain B, Ignacimuthu $\mathrm{S}$, et al. Mechanisms of plant defense against insect herbivores. Plant Signal Behav. 2012;7(10):1306-20.

21. Wardle DA, Nilsson M-C, Gallet C, Zackrisson O. An ecosystemlevel perspective of allelopathy. Biol Rev. 1998;73(3):305-19. doi: 10.1111/j.1469-185X.1998.tb00033.x.

22. Rice EL. Allelopathy. New York: Academic Press; 1984.

23. Muscolo A, Panuccio MR, Sidari M. The effect of phenols on respiratory enzymes in seed germination. Plant Growth Regul. 2001;35(1):31-5. doi:10.1023/a:1013897321852.
24. Lindeberg G. Stimulation of some litter-decomposing basidiomycetes by shikimic acid. Physiol Plantarum. 1985;65(1):9-14. doi: 10.1111/j.1399-3054.1985.tb02351.x.

25. Alfredsen G, Solheim H, Slimestad R. Antifungal effect of bark extracts from some European tree species. Eur J For Res. 2008;127(5):387. doi:10.1007/s10342-008-0222-x.

26. Dübeler A, Voltmer G, Gora V, Lunderstädt J, Zeeck A. Phenols from Fagus sylvatica and their role in defence against Cryptococcus fagisuga. Phytochemistry. 1997;45(1):51-7. doi:10.1016/S00319422(96)00771-6.

27. Petrakis PV, Spanos K, Feest A, Daskalakou E. Phenols in leaves and bark of Fagus sylvatica as determinants of insect occurrences. Int J Mol Sci. 2011;12(5):2769-82. doi:10.3390/ijms12052769.

28. Boeckler GA, Gershenzon J, Unsicker SB. Gypsy moth caterpillar feeding has only a marginal impact on phenolic compounds in oldgrowth black poplar. J Chem Ecol. 2013;39(10):1301-12. doi:10. 1007/s10886-013-0350-8.

29. Crecelius A, Clench MR, Richards DS. TLC-MALDI in pharmaceutical analysis. Spectroscopy. 2004;28-34.

30. Kulkarni P, Kaftan F, Kynast P, Svatos A, Bocker S. Correcting mass shifts: a lock mass-free recalibration procedure for mass spectrometry imaging data. Anal Bioanal Chem. 2015;407(25):7603-13.

31. Liebeke M, Strittmatter N, Fearn S, Morgan AJ, Kille P, Fuchser J et al. Unique metabolites protect earthworms against plant polyphenols. Nat Commun. 2015;6.

32. Cipollini D, Stevenson R, Enright S, Eyles A, Bonello P. Phenolic metabolites in leaves of the invasive shrub, Lonicera maackii, and their potential phytotoxic and anti-herbivore effects. J Chem Ecol. 2008;34(2): 144-52.

33. Kessler A, Baldwin IT. Plant responses to insect herbivory: the emerging molecular analysis. Annu Rev Plant Biol. 2002;53:299 328.

34. Furstenberg-Hagg J, Zagrobelny M, Bak S. Plant defense against insect herbivores. Int J Mol Sci. 2013;14(5):10242-97. doi:10. 3390/ijms140510242.

35. Wu J, Baldwin IT. New insights into plant responses to the attack from insect herbivores. Annu Rev Genet. 2010;44(1):1-24. doi:10. 1146/annurev-genet-102209-163500.

36. Simmonds MSJ. Flavonoid-insect interactions: recent advances in our knowledge. Phytochemistry. 2003;64(1):21-30.

37. Scognamiglio M, Esposito A, D’Abrosca B, Pacifico S, Fiumano V, Tsafantakis $\mathrm{N}$, et al. Isolation, distribution and allelopathic effect of caffeic acid derivatives from Bellis perennis L. Biochem Syst and Ecol. 2012;43:108-13. doi:10.1016/j.bse.2012.02.025.

38. Hauck B, Gallagher JA, Morris SM, Leemans D, Winters AL. Soluble phenolic compounds in fresh and ensiled orchard grass (Dactylis glomerata L.), a common species in permanent pastures with potential as a biomass feedstock. J Agric Food Chem. 2014;62(2):468-75.

39. Wojakowska A, Perkowski J, Góral T, Stobiecki M. Structural characterization of flavonoid glycosides from leaves of wheat (Triticum aestivum $\mathrm{L}$.) using LC/MS/MS profiling of the target compounds. J Mass Spectrom. 2013;48(3):329-39. doi:10.1002/jms.3160.

40. Griffiths DW. The inhibition of digestive enzymes by polyphenolic compounds. Adv Exp Med Biol. 1986;199:509-16. 